\title{
Peculiarities of success performance of women in codependent relationship in a changing society
}

\author{
Irina Abakumova ${ }^{1}$, Anastasia Kolenova ${ }^{1, *}$, and Marina Elagina ${ }^{1}$ \\ ${ }^{1}$ Don State Technical University, Rostov on Don 344000, Russia
}

\begin{abstract}
Dynamism in culture and personal value orientations leave their mark on such a socio-cultural phenomenon as success. It is classified as one of those concepts, the life meaning of which is clearly understood by everyday consciousness, but its psychological essence is sometimes not obvious due to the multifaceted nature of its meanings and relationships, expressed in its semantics. It was proved that codependent relationships affect the value-semantic sphere of the codependent, the content characteristics of the value-semantic sphere of the codependent change. Among other things, ideas about one's own life, one's future may change, the image of the I and the image of the world, the idea of success, change. The study involved 167 participants - women in codependent relationships. Research methods: methodology "Research of ideas about successful professional activity" (O. Yu. Klochkova); methodology "Motivation for success and fear of failure" (A. A. Rean); methodology "Self-assessment of manifestations of fear of success" (G.V. Turetskaya); scale of measuring codependency in relationships (L. Spann-D. Fisher, adapted by V.D. Moskalenko). Statistical analysis and data processing were performed using the «Microsoft Excel 7.0» и «SPSS» (22.0). Our comparative analysis of the data made it possible to reveal that there are significant differences in the indicators of ideas about success among women with a high and normal level of codependency, and there is also a relationship between the level of codependency and ideas about success.
\end{abstract}

\section{Introduction}

The change in the basic structures of Russian society, the rapid transformation of the environment, contributes to a change in human life. And this directly affects the psychological state of a person, is reflected in professional self-realization, and is a stimulus for the development of personality.

Dynamism in culture and personal value orientations leave their mark on such a sociocultural phenomenon as success. It is classified as one of those concepts, the life meaning of which is clearly understood by everyday consciousness, but its psychological essence is sometimes not obvious due to the multifaceted nature of its meanings and relationships, expressed in its semantics. Due attention is paid to the problems of success in psychological

\footnotetext{
*Corresponding author: Kolenova.nastya@ya.ru
} 
science. It is considered from different theoretical positions and studied in foreign science such as: S. Bandura, A. Maslow, K. Levin, D. Kuhn, L. Monahan, F. Salili, P. Shaver, K. Shibe and others [3]. However, people in codependent relationships tend to lack the necessary skills, resulting in dysfunctional relationships and ineffective functioning. As a phenomenon, "Co-dependence" (codependency) has been isolated in psychology relatively recently. Nobody knows exactly where, when and who first used this term. At first, this concept was understood as a life together or a close relationship with an alcoholic or drug addict. Then it became associated also with living together or intimate relationships with any disfunctional person. In the general sense of the word: Codependency is the constant concentration of thought on someone or something and dependence (emotional, social, sometimes physical) on a person or object. Sometimes this dependence on another person becomes a pathological condition that affects all other relationships $[2,6,16]$. The basis of the research is the works devoted to the study of the problem of codependency of such foreign authors as M. Beatty, R. Subby, E. Larsen, Wecksheider-Cruz, G. Claud, E. Smith, A. Mager, M. Beatty, P. Kaufmann, E. Smith, B. Winehold, J. Winehold. Nature research E. Fromm, E. Bern, K. Rogers and others $[7,8,9,11,13,18,19,20]$.

In modern times, society is characterized by people's desire for material values and various components of comfort. This gives rise to the cult of external success, the desire to possess a considerable amount of money, self-determination in professional activity and the achievement of high positions, the constant receipt of various pleasures, etc. Quantity is now recognized as a measure of success [12].

Many scientists identify the orientation of the individual towards achieving success as an integral part of the development of the individual and society [1].

We will adhere to the position that success and success are identical concepts. And accordingly, by success, we mean - a positive result of the subject's activities to achieve goals that are significant for him, reflecting the social guidelines of society [21]. Highlighting the criteria for success, we see the following division into external and internal, the first refers to the visible achievements of a person, the second refers to the internal world of a person and how the achievement of the goal affects him. But the main criterion among all is the feeling of satisfaction with one's life in general.

Studies of codependent behavior are usually conducted in the mainstream of the study of the communicative sphere, correction of codependency, the relationship of codependency with various addictions, there are very few studies devoted to changes in the meaning and life ideas of a codependent personality, we have not come across studies of changes in ideas about success.

\section{Materials and methods}

Methodology "Research of ideas about successful professional activity" (O. Yu. Klochkova); methodology "Motivation for success and fear of failure" (A. A. Rean); methodology "Selfassessment of manifestations of fear of success" (G.V. Turetskaya); scale of measuring codependency in relationships (L. Spann-D. Fisher, adapted by V.D. Moskalenko). Statistical analysis and data pro-cessing were performed using the «Microsoft Excel 7.0» и «SPSS» (22.0). The significance of the differences was taken at $\mathrm{p}<0.05$.

The sample. The study involved 167 women, age 29-35, in a relationship. Based on the test "Scale for measuring codependency in relationships" (L. Spann-D. Fisher, adapted by V. D. Moskalenko), the sample was divided into 2 subgroups of 47 people: women with a normal level of codependency, women with pronounced codependency. 


\section{Results}

We will consistently describe the most significant results of each of the methods and their comparison, and then give a general description of the identified features. Consider the meaning of the manifestation of codependency in relationships in women. Using the Test for Codependency (D. Fisher, L. Spann, adaptation by V. D. Moskalenko) we assessed the level of severity of codependency among respondents.

Table 1 shows the results of a molecular genetic analysis of the distribution of polymorphic MAOA variants in the sample.

Table 1. Test values for codependency (D. Fisher, L. Spann, adaptation by V.D. Moskalenko) (in percent).

\begin{tabular}{|c|c|c|c|}
\hline \multicolumn{2}{|r|}{ Variables } & $\begin{array}{c}\text { Sample size } \\
\text { (subgroups N) }\end{array}$ & $\%$ \\
\hline \multirow{3}{*}{ 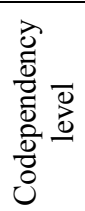 } & Normal & 50 & 30 \\
\hline & Moderate codependency & 70 & 42 \\
\hline & Severe codependency & 47 & 28 \\
\hline
\end{tabular}

Evaluating the values of the indicators, we can see that the most pronounced moderately pronounced codependency in $42 \%$ of women. Respondents of this group tend in some situations to inadequately evaluate soybeans relationships, for example, during a state of love, sometimes they experience a strong emotional dependence on their partner. 30\% of the women surveyed have a normal level of codependency. They know how to adequately assess their relationships with other people, can prioritize the satisfaction of their own and others' needs, build "healthy" relationships. Respondents with a normal level of codependency tend to adequately assess relationships and are able to prioritize interpersonal interaction and meet the needs of both their own and others. The least pronounced codependency in the total sample is observed, observed in $28 \%$ of women. Such women show a strong physical, emotional and physical dependence on the object of codependent relationships, it is difficult for them to imagine life without an addict. At the same time, codependency is often not recognized, a woman considers such relationships to be the norm and often calls such relationships "close", "true love", etc.

In a further study, 94 people took part, for the purpose of a uniform sample, each subgroup included 47 people, 2 research subgroups were formed of a woman with a normal level of codependency, a woman with a pronounced codependency.

As a result of a theoretical analysis of ideas about success, we identified a number of components, which we studied further in an empirical study: models of success, motivation for success, manifestation of success; ideas about the specifics of achieving success.

The data obtained using the methodology "Research of perceptions of success" (O. Klochkova) are presented in Table 2. The methodology allows you to study the models of women's success.

Table 2. Distribution of success models among respondents.

\begin{tabular}{|l|c|c|}
\hline \multicolumn{2}{|c|}{ Success models } & Results \\
\hline \multirow{2}{*}{ Compromise } & $\mathrm{N}$ & 39 \\
\cline { 2 - 3 } & $\%$ & 41.9 \\
\hline \multirow{2}{*}{ American } & $\mathrm{N}$ & 25 \\
\cline { 2 - 3 } & $\%$ & 26.3 \\
\hline \multirow{2}{*}{ Soviet } & $\mathrm{N}$ & 14 \\
\cline { 2 - 3 } & $\%$ & 15.2 \\
\hline
\end{tabular}




\begin{tabular}{|l|c|c|}
\hline \multirow{2}{*}{ Hedonistic } & $\mathrm{N}$ & 9 \\
\cline { 2 - 3 } & $\%$ & 9.3 \\
\hline Ascetic & $\mathrm{N}$ & 7 \\
\hline & $\%$ & 7.3 \\
\hline
\end{tabular}

Thus, a compromise model of achieving success prevails with a result of $41.9 \%$. Women with a compromise model accept success as a "private life", this model is considered accepted and approved by loved ones. For this type of people, material factors are significant, but this does not play a big role in this case.

The American model occupies the next position of $26.3 \%$ of the subjects, which includes material success in the main goal, the achievement of which is possible only through hard work. They pay attention to the moral success of a person, achieved without violating the norms of society, as a necessary contribution to the improvement of society. The Soviet model has $15.2 \%$. For women focused on this model, earning big money takes the last place in life, the emphasis is on value-rational actions. Achievement of success goes "through education to the intelligentsia", which is based on the prestige and usefulness of the profession. Such women often choose professions that are socially approved (teacher, educator, doctor), but at the same time they are poorly paid. The hedonic model is much less represented $-9.3 \%$. Women with this model of success prioritize receiving various personal pleasures obtained with the help of material security, choosing a professional activity or an activity of personal realization, they are looking for the greatest material benefit in order to obtain further pleasures. The least represented is the ascetic model of $7.3 \%$, which leads the refusal of any pleasures that the material world gives, women choosing this model are ready to work for an "idea", denying themselves any benefits.

On the basis of our methodology "Motivation for success and fear of failure" by A.A. Rean, the results were presented in Table 3.

Table 3. Distribution of success motivation and fear of failure among respondents.

\begin{tabular}{|l|c|c|}
\hline \multicolumn{2}{|c|}{ Focus of achievement motivation } & Results \\
\hline \multirow{2}{*}{ Motivation for success } & $\mathrm{N}$ & 46 \\
\cline { 2 - 3 } & $\%$ & 49.1 \\
\hline \multirow{2}{*}{ Motivation to fail } & $\mathrm{N}$ & 43 \\
\cline { 2 - 3 } & $\%$ & 45.4 \\
\hline \multirow{2}{*}{ The motivational pole is not pronounced } & $\mathrm{N}$ & 5 \\
\cline { 2 - 3 } & $\%$ & 5.5 \\
\hline
\end{tabular}

The largest number of respondents are focused on achieving success in their activities. Having such motivation, when starting a business, a person initially has in mind only a positive result and is ready to solve problems and confidently face failures, but, in his opinion, there should be only one outcome - achieving a result.

The results according to the methodology "Self-assessment of manifestations of fear of success" (G.V. Turetskaya) are presented in Picture 1, the data obtained allow us to analyze how expressed the fear of success among the respondents. 


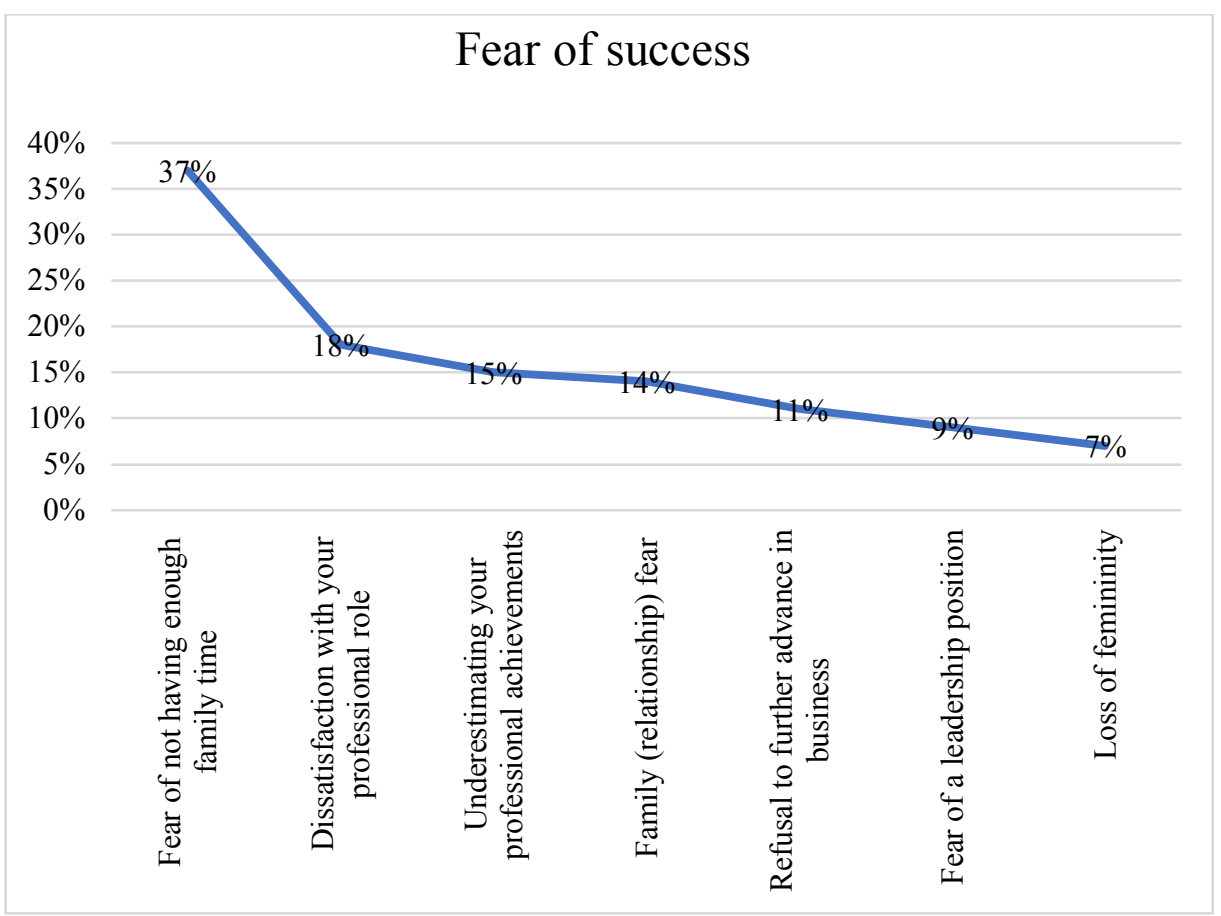

Fig. 1. Indicators of respondents' fear of success.

As a result of studying the main manifestations of fear of success among women, we found that the majority of respondents (37\%) experience significant anxiety about the insufficient time and attention given to their family or loved ones. They worry that if a significant level of success is achieved in any area or on the path to achieving success, there will be a significant lack of time. when climbing the ladder of success, considerable effort is needed.

We carried out Pearson's correlation analysis. There is a relationship between the high level of association and the performance of women's perceptions of success. The relationship was revealed by the ascetic model of success $(r=0.67$, with $\mathrm{p}<0.05)$. The relationship with the Soviet model of success $(r=0.45$, at $p<0.05)$ indicates that women are focused on professions recognized as socially useful. An inverse relationship was found between a high level of codependency and a hedonistic model of success $(r=-0.51$, at $p<0.05)$, the higher the level of codependency in women, the less they strive for any kind of pleasure. A high level of women's codependency is associated with the fear of not having enough time devoted to the family $(\mathrm{r}=0.56$, at $\mathrm{p}<0.05)$, with the fear of preserving the family $(\mathrm{r}=0.53$, at $\mathrm{p}<$ $0.05)$ and with the fear of a leadership position $(\mathrm{r}=0.65$, at $\mathrm{p}<0.05)$. We found a relationship between a high level of codependency and an orientation toward failure $(r=0.48$, at $p<$ 0.05 ). The desire to avoid failure and any negative consequences provokes women to achieve, but there is no faith in their own strength.

There is a relationship between the normal level of codependency and the performance of women's perceptions of success. A relationship with the hedonistic model of success was revealed $(r=0.57$, at $\mathrm{p}<0.05)$, thus, the lower the level of codependency, the more women are characterized by the hedonistic model. The relationship with the American model of success $(r=0.45$, at $\mathrm{p}<0.05)$ indicates that the more women are willing to work hard to achieve material success. The normal level of female codependency is inversely related to the fear of not having enough time devoted to the family $(\mathrm{r}=-0.65$, at $\mathrm{p}<0.05)$ and with the fear of a leadership position $(\mathrm{r}=-0.51$, at $\mathrm{p}<0.05)$. The revealed direct correlation 
relationship between the normal level of codependency and dissatisfaction with one's professional role $(r=0.48$, at $\mathrm{p}<0.05)$ indicates that the lower the level of codependency, the higher the fear of not being realized in the profession. We found a relationship between the normal level of codependency and the orientation toward success $(r=0.45$, at $p<0.05)$. The more successful women are, the less codependent they are.

\section{Discussions}

Many researchers, considering "success" from a phenomenological point of view, say that it is originally embedded in the human structure of existence. In his works, D. McClelland said that a person who is oriented towards success takes calculated risks. Such people do not prefer easy tasks because they do not feel that they will bring them success, however, they do not set difficult tasks, realizing that they can lead to failure. Highlighting the criteria for success, we see the following division into external and internal, the first refers to the visible achievements of a person, the second refers to the internal world of a person and how the achievement of the goal affects him.

However, people in codependent relationships tend to lack the necessary skills, resulting in dysfunctional relationships and ineffective functioning. Codependency is a certain transformation of the value-semantic sphere of a person, caused by stable learned patterns of behavior in interaction with significant Others, mediating attitude towards oneself and all other relationships $[2,6,9]$. Thus, codependency, being an adaptation to significant life events, includes the subsequent profound transformations of the value-semantic sphere of the personality in the form of: changes in attitudes towards a significant Other and towards yourself personally; restructuring of life goals and value orientations under the influence of a significant Other; distribution of responsibility for oneself and the life of the Other [11, 16, $19,20]$. Thus, we see that both the concept of "codependency" and the concept of "success" are based on the semantic sphere of a person.

\section{Conclusions}

Our research is an attempt to identify the features of the ideas about success among women with different levels of codependency. The subject of the research is the study of the peculiarities of ideas about success among women with different levels of codependency:

1) In our sample, moderately pronounced codependency is most pronounced in $42 \%$ of women. $30 \%$ of the women surveyed have a normal level of codependency. They know how to adequately assess their relationships with other people. The least pronounced codependency in the total sample is observed, observed in $28 \%$ of women. Such women show strong physical, emotional and physical dependence on the object of codependent relationship.

2) There is a relationship between the severity of codependency and indicators of perceptions of success in women.

3) There are peculiarities of ideas about success among women in codependent relationships.

The comparative analysis of the data made it possible to reveal that there are significant differences in the indicators of ideas about success among women with a high and normal level of codependency, and there is also a relationship between the level of codependency and ideas about success. 


\section{Acknowledgements}

This research was funded by the Russian Foundation for Basic Research (RFBR), project № 18-013-01209.

\section{References}

1. I. Abakumova, L. Kruteleva, E. Ryadinskaya, 6th.World Congress of Psychology and Behavioral Sciences (Management, Psychology, Political and Social Sciences) (WCPBS 2016) (Universitat Barcelona, 2016)

2. M. Beattie, Beyond Codependency and getting better all the time (Harper \& Row, San Francisco, 1989)

3. R.F. Bornstein, American Psychologist 61(6), 595-606 (2006) http://dx.doi.org/10.1037/0003-066X.61.6.595

4. J.A. Fuller, R.M. Warner, Genetic, social, and general psychology monographs 126(1), 5-22 (2000)

5. S. Karpman, A Game Free Life (Self Published, San Francisco, 2014)

6. E. Larsen, Stage II Recover: Life Beyond Addiction (Harper \& Row, San Francisco, 1985)

7. C. McMillen, S. Zuravin, G. Rideout, Journal of Consulting and Clinical Psychology 63(4), 1037-1043 (1995)

8. W. Mendenhall, Course on Co-dependence (New Brunswick, NJ, 1987)

9. P. Mellody, Facing Love Addiction: Giving Yourself the Power to Change the Way You Love (Hazelden Publishing, Wickenburg, 2003)

10. S. Sarkar, S.K. Mattoo, D. Basu, J. Gupta, International Journal of Culture and Mental Health 8(1), 13-21 (2015) https://doi.org/10.1080/17542863.2013.868502

11. A.W. Schaef, Co-Dependence Misunderstood-Mistreated (Harper \& Row, New York, 1986)

12. M. Shafer,, Psychoter. Psychosom. Med. Psychol. 50(2), 38-50 (2000)

13. R. Subby, J. Friel, Co-dependency: A Paradoxica Dependency in Co-Dependency: An Emerging Issue (Health Communications, Pompano Beach, FL, 1984)

14. Y. Ulusoy, S.S. Guçray, Journal of International Social Research 10(49) (2017)

15. F.E. Vasilyuk, Journal of Russian \& East European Psychology 52(1), 1-58 (2015)

16. S. Wegscheider-Cruse, Choicemaking: For Co-dependents, Adult Children And Spirituality Seekers. Health Communications (Pompano Beach, FL, 1985)

17. M.C. Wells, M.B. Hill, G. Brack, C.J. Brack, E.E. Firestone, Journal of College Student Psychotherapy 20(4), 71-84 (2006)

18. C.L. Whitefield, Alcohol.Treat.Quart. 6(1), 19-36 (1989)

19. CL. Whitfield, Codependence: Healing the Human Condition: The New Paradigm For Helping Professionals And People In Recovery. Health Communications (Deerfield Beach, FL, 1991)

20. E. Young, J. Psychoactive Drugs. 19(3), 257-268 (1987)

21. U. Zetterlind, M. Berglund, Nordic Journal of Psychiatry 53(2), 147-151 (1999) 